\title{
A MATHEMATICAL MODEL FOR PREDATOR AND PREY POPULATIONS
}

\author{
Kenneth R. DixoN ${ }^{1}$ and George W. CoRNWELL \\ School of Forestry, University of Florida, Gainesville, Florida, U.S. A.
}

The study of predator-prey relationships has always been associated with the use of mathematical models. Until recently these models, such as those of LoTkA and VOLTERRA, have had little basis in the real world. The more recent models of HoLling $(1965,1966)$ and WATT $(1959)$ have dealt primarily with the mechanics of predation itself. Relatively few models of natural populations have been developed primarily due to the complexity of such systems. The model developed in this paper, for a single predator and prey species system, can be used to simulate both predator and prey populations over a period of time, providing a means for predicting future populations, including equilibrium levels. Analysis of the system is possible by varying the parameters in the system. In the present paper, the model is used to simulate the predator-prey system on Isle Royale, in which moose (Alces alces) are the only large herbivore and wolves (Canis lupus) the only large predator.

We wish to acknowledge the assistance of R. L. PATterson in developing the model. Also, D. L. Allen and P. A. Jordan were kind enough to allow the use of unpublished data from their studies on Isle Royale. We wish to thank R. G. SELFrIDGE. Director of the University of Florida Computer Center, for computer time.

\section{The Mathematical Model}

\section{Development of the Model}

In attempting to model any natural system, we are faced with the problem of determining whether the model is a true reflection of the real world. A particular component or subsystem of the model can be tested under laboratory conditions, but this response should be observed in the field if it is to apply. On the other hand, the model could be based on data obtained in the natural system, but there it is not possible to measure the full range of any response. The present model uses both parameters measured in the real world and models developed in the laboratory.

The model consists of a set of difference equations, one for a predator population and a second for a prey population. Each equation contains individual terms to express various components of the system. A model of this type is easily programmed for simulation on a digital computer.

In general, the model takes the form:

${ }^{1}$ Present address: Department of Wildlife and Fisheries, University of Michigan, Ann Arbor, Michigan, U.S.A. 


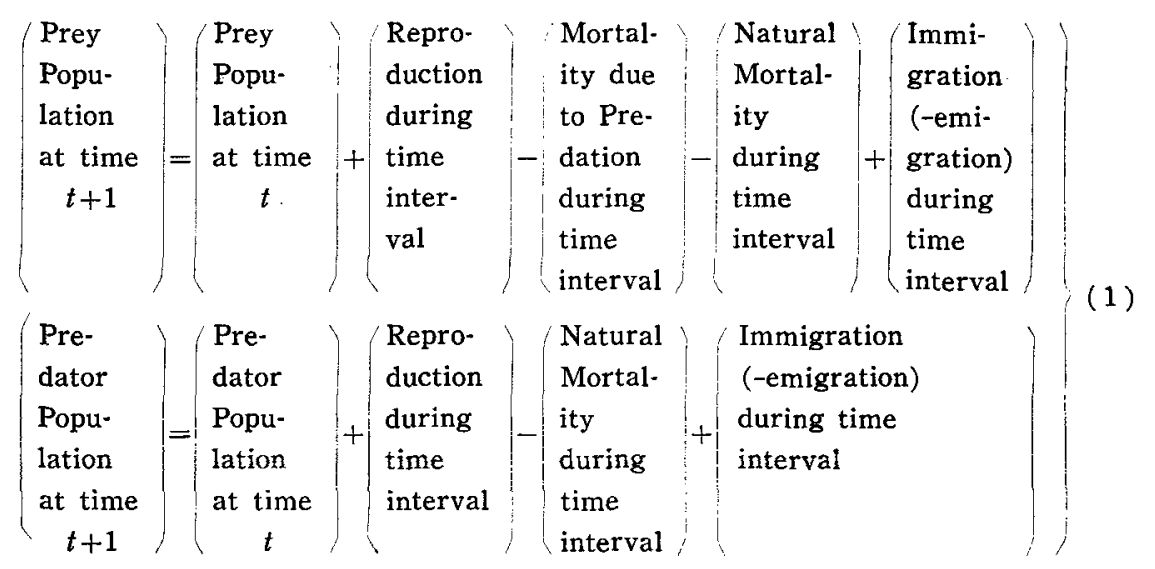

Each term of equations (1) represents a component of the model and can be expressed as a time-dependent equation itself.

The component equations will depend on the particular system being studied, the predator and prey species, and the form of the responses in the system. For further development of the model it is necessary to consider a particular application with its specific components.

\section{An Application of the Model}

The predator-prey system of wolves and moose on Isle Royale National Park offers several advantages for applying a model of this type. The interspecies relationships are relatively simple with moose being the only large herbivore and wolves the only large predator on the island. Immigration and emigration are relatively insignificant in the present dynamics of both populations and are disregarded in this model.

The present moose population became established by immigration from the mainland in the early 1900's (MEcH 1966:21). The population increased until, by 1928, estimates reach 5000 individuals ( $\mathrm{MECH} 1966: 22$ ) at which time the population crashed to a low of 171 . The moose population continued to fluctuate until wolves became established in the early 1950's (MECH 1966:24). Since then, the two populations have reached a dynamic equilibrium with moose numbering approximately 600 and wolves numbering 22. Each population is relatively stable, with fluctuations in one being compensated for by the other until equilibrium again is reached ( $\mathrm{MECH} 1966: 167$ ).

According to $\mathrm{MECH}(1966: 114)$, natural mortality in moose on Isle Royale is insignificant compared to mortality due to predation, and since there is little information on this component before wolves became established on the island, it is not included in this first model.

Two components are of particular importance. These are two interaction terms in which the response is a function of both predator and prey populations.

One of these components, the mortality of prey due to predation, is the functional response described by Holling (1965). The best mathematical model of this response 
to date is that of WATT (1959) which includes the concept of a limited attack rate and competition between predators.

This model, in the case of mammals, follows:

$$
N_{a}=P K_{1}\left[1-e^{-a N_{0}^{2} P^{1^{-c}}}\right]
$$

where $N_{a}=$ number of prey attacked

$N_{0}=$ initial number of prey

$P=$ number of predators

$K_{1}=$ maximum number of attacks that can be made per $P$

and $a$ and $c$ are constants. In time dependent form equation (2) becomes

$$
N_{a}(t)=P(t) K_{1}\left[1-e^{-a N_{0}(t)^{2} P(t)^{1-c}}\right]
$$

Constants for equation (2) can be calculated as follows. If 227 moose were killed annually (MECH 1966:163), one moose is killed, on the average, every 1.6 days (or 0.62 moose per day). This rate is undoubtedly less than the maximum possible. The maximum rate of predation, $K_{1}$, can be estimated from rates of predation observed over short periods of time. $\mathrm{MeCH}(1966: 117,143)$ observed 6 moose killed during a total of 68 hours of hunting by the large pack of wolves. This gives a value of 2.9 moose killed per day by the total wolf population, or a value of $K_{1}$ of 48.1 moose per wolf per year. Other estimates of $K_{1}$ can be obtained by similar observations of rates of predation. Once $K_{\mathrm{I}}$ has been estimated, the constants $a$ and $c$ can be determined by solving equation (2) using initial populations of 22 wolves and 600 moose and 227 moose killed. When equation (2) is solved for different prey density values, $N_{\alpha}$ can be plotted against prey density to obtain the wolf functional response curve (Fig. 1).

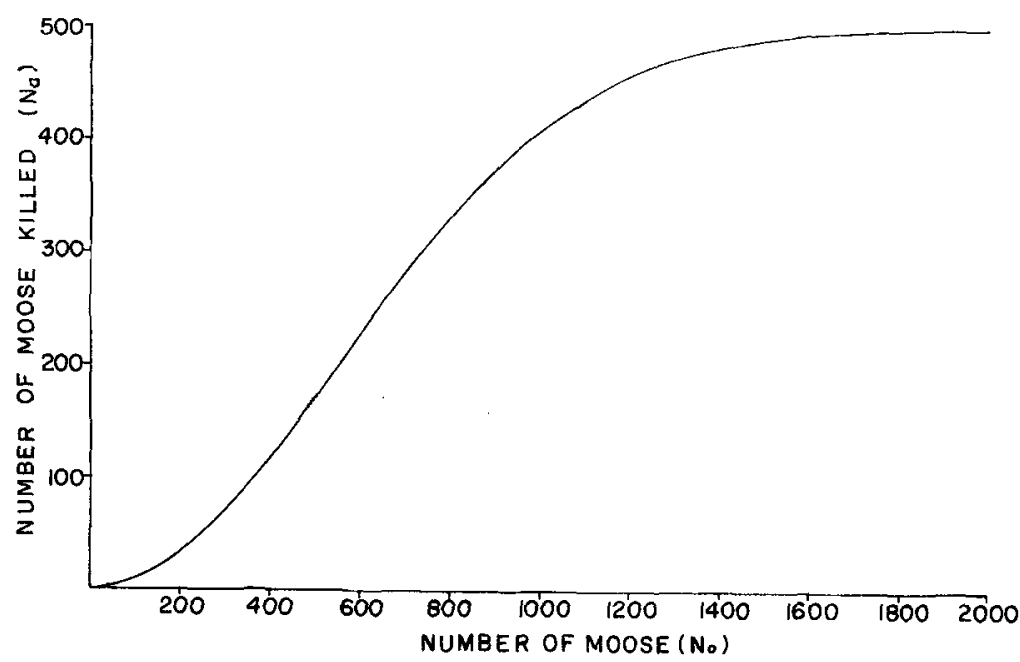

Fig. 1. Estimated functional response of 22 wolves to moose density on Isle Royale. The maximum annual predation rate per wolf, $K_{1}$, is 22.73 . 
The second interaction component is predator reproduction. In some predator species such as wolves (JORDAN et al. 1967), reproduction has a threshold response in that successful reproduction occurs mainly when the number of prey is above a certain level.

This observation is supported by laboratory studies of reproduction in dogs. SIEDLER and ScHWEIGERT (1954) found that reproduction performance of bitches was improved with the addition of animal fat to the diet provided dilution of other nutrients did not occur. Bitches fed a protein or liver supplement bore pups with higher birth weights and increased survival to weaning (ONTKo and PHILlips 1958).

At present, there is no model available for this reproductive response. The models of fecundity which have been developed are primarily a function of the predator population density (WATT 1968:295) and do not consider the density of the prey species or nutrition level of the predator. A model of this response can be obtained from a logical branching tree such as that published by WATT (1961). Equation (4) states that all predators can produce a total of $P K_{2}$ offspring and $d P_{b} / d N_{0}$ gradually decreases as $P_{b}$ approaches this maximum.

$$
\frac{d P_{b}}{d N_{0}}=P B\left(P K_{2}-P_{b}\right)
$$

where $P_{b}=$ number of predator offspring

$N_{0}=$ number of prey

$P=$ number of predators

$B=$ birth rate of predators, the $P_{b}$ per $P$

$K_{2}=$ maximum number of offspring that can be produced per $P$

However, the birth rate has been shown to be a density-dependent function of $P$ in some mammals (CHRISTIAN 1956), so that,

$$
\frac{d B}{d \bar{P}}=-g \frac{B}{P}
$$

which integrates to

$$
B=f^{\prime} P^{-g}
$$

Substituting (6) in equation (4)

$$
\frac{d P_{b}}{d N_{0}}=f^{\prime} P^{1-g}\left(P K_{2}-P_{b}\right)
$$

and, upon integrating

$$
P_{b}=P K_{2}\left[1-e^{-f^{\prime} N_{0} P^{1-o}}\right]
$$

To allow for the threshold response the form of equation (7) is made S-shaped,

$$
P_{b}=P K_{2}\left[1-e^{-f N_{0}^{2} P^{1-g}}\right]
$$

converting to a time dependent form, equation (8) becomes

$$
P_{b}(t)=P(t) K_{2}\left[1-e-f N_{0}(t)^{2} P(t)^{1-\theta}\right]
$$

Predator reproduction will contribute to the numerical response (Holling 1961) of predators to prey density and the term $P_{b}$ can be considered the reproductive 
response to prey density.

The maximum reproductive rate of wolves, $K_{2}$, in equation (8) depends not only on wolf fecundity but also on the sex ratio of the population. $\mathrm{MECH}$ (1966:87) believes there is a preponderence of males in the population and possibly as few as 5 females out of the 22 wolves. If we assume a possible litter size of 7 (Young and Goldman 1944:96), our value of $K_{2}$ is 1.6 young per wolf per year. However, if a 50:50 sex ratio existed the value is 3.5 young per wolf per year. Constants $f$ and $g$ in equation (8) are determined in the same way as constants $a$ and $c$ were in equation (2).

Components, other than the above interaction components can be expressed as equations or approximated by constants.

The particular model for the Isle Royale system then consists of the following equations:

$$
N_{0}(t+1)=N_{0}(t)+b N_{0}(t)-N_{a}(t)
$$

for the prey population, and

$$
P(t+1)=P(t)+P_{b}(t)-d P(t)
$$

for the predator population

$$
\text { where } \begin{aligned}
N_{0}(t+1) & =\text { prey population at time } t+1 \\
N_{0}(t) & =\text { prey population at time } t \\
b & =\text { prey birth rate } \\
N_{a}(t) & =\text { equation }(3) \\
P(t+1) & =\text { predator population at time } t+1 \\
P(t) & =\text { predator population at time } t \\
P_{b}(t) & =\text { equation }(9) \\
d & =\text { death rate of predators }
\end{aligned}
$$

Values for the parameters in equations (10) and (11) now can be calculated.

The prey birth rate $b$ is determined by dividing the number of offspring by the population size at calving time. The number of offspring is 227 (MECH 1966:162) and the population at calving time is 574 (Shelton 1966:263) which give a value of $b=$ $227 / 574=.395$ for an estimate of birth rate in the moose population.

Reproduction and adult mortality do not take place on an annual basis in the wolf population, although successful reproduction occurs only when there has been mortality in the adult wolves or an increase in the moose population (JoRDAN, et al. 1967). Since there is a balance between reproduction and mortality, equation (9) and a constant rate of mortality are each calculated on an annual basis of one wolf per year.

The estimated value of wolf mortality is $d=1 / 22=.045$, based on an initial population of 22 wolves.

After all parameters have been determined, the components are assembled in equations (10) and (11) and programmed for simulation on a digital computer. To test the assumption of stable populations, the program first was run using the estimated 
populations of 22 wolves and 600 moose. Then the initial population levels and various parameter values were varied to analyze their effects on the dynamics of the system.

\section{Results and Conclusions}

\section{Validation of the Model}

Validation of the model required testing the model's stability and determining how accurately the model represents the natural system. To test the stability of the model, a simulation was run using the assumed equilibrium populations of 600 moose and 22 wolves. Values for $K_{1}$ and $K_{2}$ are 45.45 and 1.60 respectively. Under these conditions the population levels should remain constant. As seen in Fig. 2, the model reflects our assumed conditions quite well. The variation within the twenty year period probably is due to rounding errors in the parameter estimates being multiplied through each iteration.

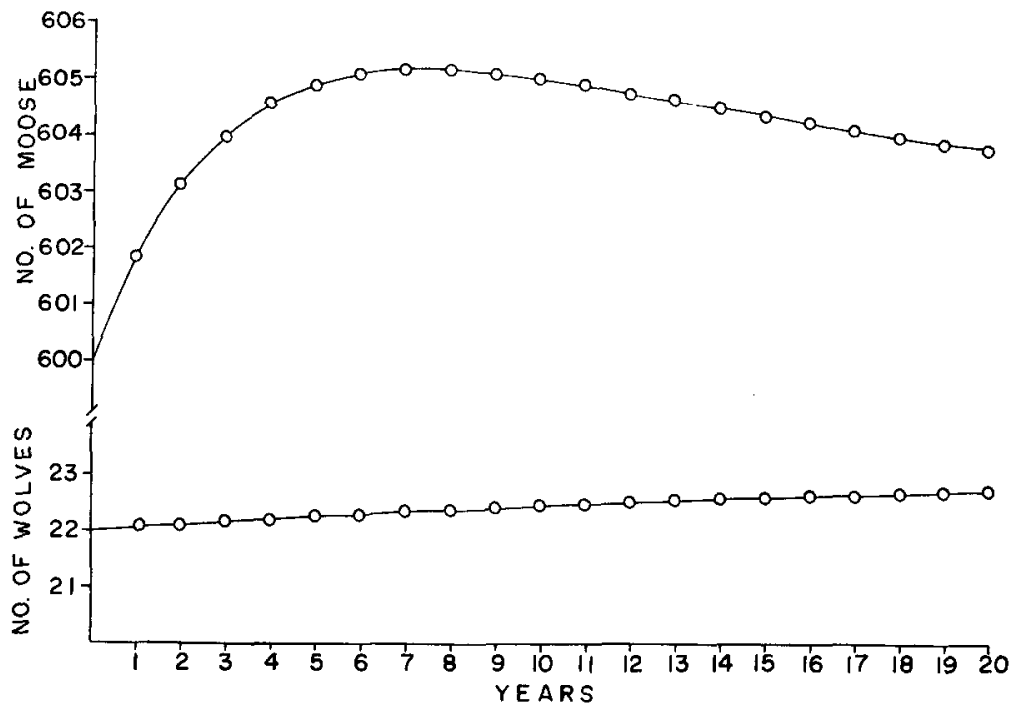

Fig. 2. Simulated coaction of assumed equibrium populations of 22 wolves and 600 moose. The maximum annual predation rate per wolf, $K_{1}$, is 45.45 the maximum annual predator birth rate per wolf, $K_{2}$, is 1.60 , and the prey birth rate, $b$, is 0.395 .

In the natural world, inputs into the system, in the form of changes in the prey food supply, would cause fluctuations about this equilibrium and in other simulations as well.

A series of simulations were run, varying the parameter values over a wide range, to determine the stability of the model. An attempt was made to cause both predator and prey populations to go to zero. By decreasing the predator mortality and prey reproduction, the two populations declined but could not be forced to zero regardless of the initial levels. The populations could be decimated, however, by 
changing the functional response to prey density allowing a greater rate of predation at all population densities. This required changing the response parameters beyond the range of possible values inherent in the wolf-moose system of Isle Royale. This suggests that the stability in the model of the Isle Royale system is a function of the system parameters and not a characteristic of the model.

Testing the accuracy of the model is difficult because there are no reliable population estimates before the populations became stabilized. As the wolves and moose became integrated about 1957, there was an estimated minimum moose population of 300 (COLE, 1957) and a minimum population of 15 wolves (MECH, 1966:27). The results of the simulation of this coaction (Fig. 3), show the populations increase to a stable level as hypothesized.

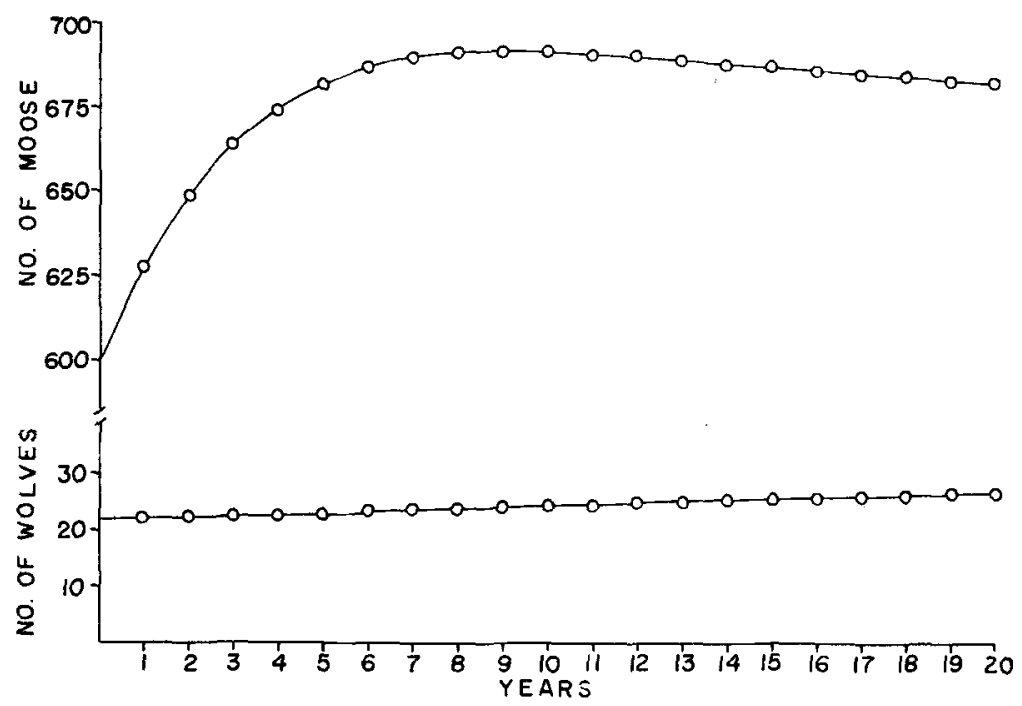

Fig. 3. Simulated coaction of the estimated 1957 populations of 15 wolves and 300 moose $\left(K_{1}=45.45, K_{2}=1.60, b=0.395\right)$.

In view of the stability and its ability to reflect the observed dynamics, the model is considered to be valid. However, it is likely that the model's accuracy can be improved when more data become available.

Uses of the Model

Once the model has been validated, there are many useful analyses which can be made.

Altering system parameters such as birth and mortality rates to examine their affects on the system can be particularly instructive.

When the prey birth rate is increased, the two populations reach a stable condition at correspondingly higher levels (Fig.4). This reflects the biological situation in which there is a permanent increase in the prey food supply, sustaining higher population levels. Otherwise natural mortality would increase, bringing the populations back to 
the original equilibrium levels. This does not occur in the simulation since natural mortality for prey is not included in the model.

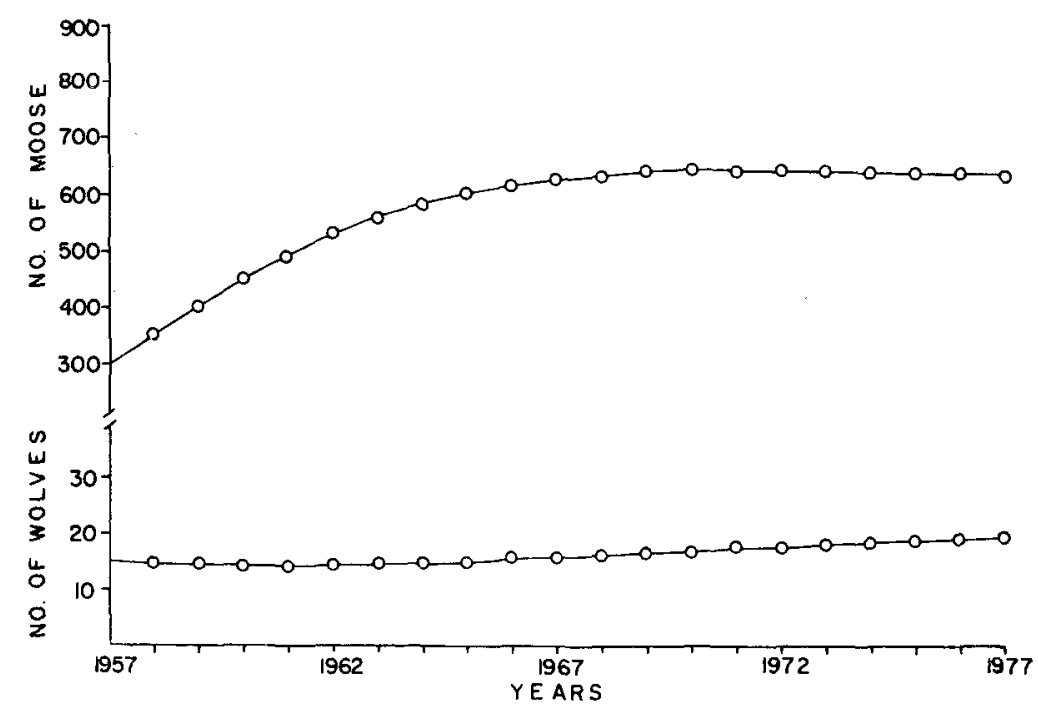

Fig. 4. Simulated coaction of 22 wolves and 600 moose with the prey birth rate, $b$, increased to 0.443 . $\left(K_{1}=45.45, K_{2}=1.60\right)$.

A series of simulations was run altering values of $K_{1}$ and $K_{2}$ to determine the best estimates of these parameters. The value of $K_{1}$ used in the simulations included in this paper, 45.45 , appears to be the best estimate of this parameter and is within the range of observed rates of predation (see page). As the value of $K_{1}$ is decreased, the functional response is slowed, allowing the prey population to increase to higher levels. Although the prey population eventually declined to an equilibrium level in every case, they peaked at later times and reached unnaturally high levels.

Changing the value of $K_{2}$ had relatively little effect because although there may be a great change in the value of $K_{2}$, there is little change in $P_{b}$, the actual predator reproduction.

Another important use of the model is the simulation of wolf-moose coactions with initial population levels that have not been observed. One such coaction pertinent to the Isle Royale system is one in which the predator population is below its stable level and the prey population is above its stable level. The results of this simulation, using 5 wolves and 1200 moose, are shown in Fig. 5 . Here, as in previous simulations, the two populations stabilize as presumed by our model. At first, the prey increase because there are too few predators to limit the population. In response, the predators increase causing a decline in the prey population. With their food supply diminishing, the predator population decreases also, and an equilibrium results.

This follows precisely MEch's (1966:168) concept of the Isle Royale system:

... if the moose population increased significantly, the wolves would find easier 


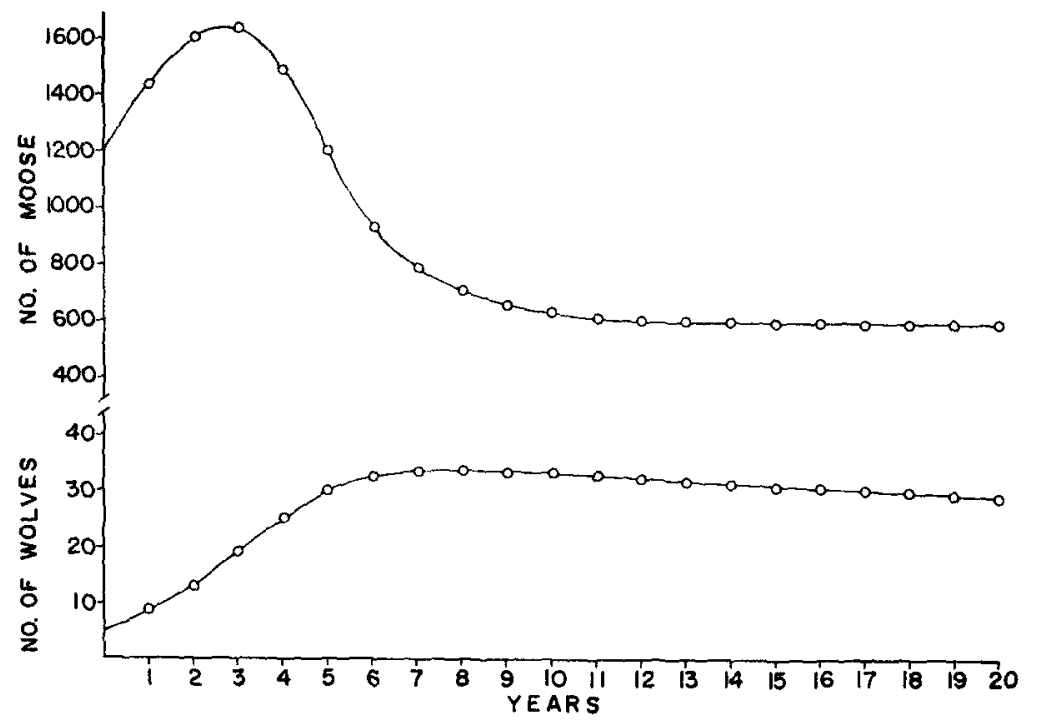

Fig. 5. Simulated coaction of 1200 moose and 5 wolves with a maximum annual predation rate per wolf, $K_{1}$, of 45.45 , a maximum annual predator birth rate, $K_{2}$, of 3.50 , and a prey birth rath rate of 0.395 .

hunting and might eat only preferred parts of their prey, as the wolves did in Minnesota when deer were more plentiful (STENLUND 1955). Increased predation then might reduce the herd to a level that again rendered hunting more difficult. Significantly, the moose population reaches a maximum level of 1600 , which is less than the population estimates (Месн, 1966:22) at the time of the moose irruption around 1930. The ability of wolves to limit the moose population, most probably at lower levels than other limiting factors, is predicted. According to the model, the wolves are able to limit the moose population over a wide range of densities, indicating the wolves are functioning as a density-dependent regulatory mechanism. The mechanism operates primarily through the feed-back effect of prey density on predator reproduction and predation rate.

In the process of modeling, the examination of the model components identifies specific gaps in our knowledge. In the present case, the effects of food supply on predator and prey reproduction should be studied, covering a wide range of population densities. Laboratory studies can confirm these effects on an energy basis, and would provide data for the development of models of these components. Although increasing the complexity of the present model is desirable, further validation is more important at this time. Continued work in the study of any ecosystem should be closely integrated with the development of models to provide the greatest understanding of those systems.

\section{Literature Cited}

Christian, J. J. (1956) Adrenal and repraductive response to population size in mice from freely 
growing populations. Ecology 37: 258-273.

CoLE, J.E. (1957) Isle Royale wildlife investigations, winter of 1956-57. Unpublished report, National Parks Service Files, Washington, D. C.

Holling, C.S. (1961) Principles of insect predation. Ann. Rev. Ent. 6: 163-182.

Holding, C.S. (1965) The functional response of predators to prey density and its role in mimicry and population regulation. Mem. Ent. Soc. Can. 45: 1-60.

Holtinc, C.S. (1966) The functional response in invertebrate predators to prey density. Mem. Ent. Soc. Can. 48: 1-85.

Jordan, P. A., P.C. Shelton, and D. L. Allen. (1967) Numbers, turnover, and social structure of the Isele Royale wolf population. Amer. Zool. 7: 233-252.

Mecr, L.D. (1966) The wolves of Isle Royale. U.S. Nat. Park Serv., Fauna Nat. Parks U.S., Fauna Ser. No. 7. 210pp.

Ontko, J.A. and P.H. Phillips. (1953) Reproduction and lactation studies with bitches fed semipurified diets. J. Nutr. 65: 211-218.

Shelton, P.S. (1966) Ecological studies of beavers, wolves, and moose in Isle Royale National Park, Michigan. Ph. D. Thesis. Purdue Univ., Lafayette, Ind. 308pp.

Siedier, A. J. and B.S.Schweigrre (1954) Effect of the level of animal fat in the diet in the maintenance, reproduction and lactation performance of dogs. J. Nutr. 53: 187-194.

Stenlund, M.H. (1955) A field study of the timber wolf (Canis lupus) on the Superior National Forest, Minnesota, Minn. Dep. Conserv., Tech. Bull. No. 4.

WATT, K.E.F. (1959) A mathematical model for the effect of densities of attacked and attacking species on the number attacked. Can. Ent. 91: 129-144.

WAtT, K.E.F. (1961) Mathematical models for use in insect pest control. Can. Ent. Supp. 19: $62 \mathrm{pp}$.

WATT, K. E. F. (1968) Ecology and resource management. McGraw-Hill, N. Y. 450pp.

Younc, S. P. and E. A. Goldman. (1944) The wolves of North America. Part I. Dover Pub. Inc., N. Y. $385 p p$.

捕食者と被捕食者の相互作用系に対する 1 数学モデル

K. R. Dixon-G. W. Cornwell

単一種どうしの捕食者一被捕食者システムに対する1つの数学的モデルを作製した。このモデルは非線型 定差方程式のかたちで表わされており，耐者の個体群の動きはコンピニーター・シミニレーションによって 容易に計算できる。とのモデルを Isle Royale 国立公園におけるオオカる (Canis lupus) とオオジカ (Alces alces）の相互作用系に適用したとてろ，両者の個体群の現実の動きがよく simulate されることがかかった。 またての場合オオカミがオオジカの個体群を制御する能力を持っているととが示唆された。 